\title{
Modulating the Genomic Programming of Adipocytes
}

\author{
Anne Loft, ${ }^{1}$ Søren Fisker Schmidt, ${ }^{1}$ and Susanne Mandrup \\ Department of Biochemistry and Molecular Biology, University of Southern Denmark, \\ Odense M 5230, Denmark \\ Correspondence: s.mandrup@bmb.sdu.dk
}

\begin{abstract}
The ability to modify the transcriptional program in response to external signals provides a way for mammalian cells to alter their biological fate and properties, thereby adapting to changes in the environment. Adipocytes are excellent examples of differentiated cells that possess a striking transcriptional plasticity when exposed to physiological and metabolic stimuli. In our work, we have focused on understanding the processes responsible for modulating the genomic programming in response to different external signals. Thus, we have shown that browning of human adipocytes with rosiglitazone, an antidiabetic agonist of the key adipocyte transcription factor peroxisome proliferator-activated receptor $\gamma(\operatorname{PPAR} \gamma)$, involves redistribution of PPAR $\gamma$ binding to form browning-selective PPAR $\gamma$ super-enhancers that drive expression of key browning genes. These include genes encoding transcriptional regulators, such as Krüppel-like factor 11 (KLF11) that are essential for modulating the genomic program in white adipocytes to induce browning. Furthermore, we have shown that acute suppression of adipocyte genes by the proinflammatory cytokine, tumor necrosis factor (TNF), involves redistribution of cofactors to enhancers activated by the master inflammatory regulator, nuclear factor kappa-light-chain-enhancer of activated B cells (NF-кB). Interestingly, this redistribution occurs selectively from enhancers with high-cofactor occupancies, thereby predominantly affecting super-enhancers and their associated genes. We propose that this is a general mechanism contributing to transcriptional repression associated with activation of signal-dependent transcription factors.
\end{abstract}

\section{INTRODUCTION}

\section{Genome-Wide Approaches to Study Adipocyte Formation and Function}

During the last decades, the use of sequencing-based genome-wide approaches has revolutionized the way we study transcriptional regulation and brought tremendous new insight into the molecular mechanisms by which transcription is regulated. For example, deep sequencing in combination with techniques that allow for identification of accessible chromatin regions, such as DNase I hypersensitivity site assessment (DNase-seq), have enabled unbiased mapping of "action points" (i.e., enhancers and promoters) throughout the genome in multiple cell types (Crawford et al. 2006; Thurman et al. 2012; Vierstra et al. 2014). Furthermore, deep sequencing combined with chromatin immunoprecipitation (ChIP-seq) has led to extensive genome-wide mapping of binding sites of transcriptional regulators (Gerstein et al. 2012; Yue et al. 2014), as well as the position of epigenomic marks (Roadmap Epigenomics Consortium et al. 2015). From these studies, it has become evident that the complexity of gene regulation far exceeds what was previously anticipated, and a major challenge is now to put the regulatory transcriptional networks into the appropriate spatial and temporal context.

One of the biological processes that have been extensively characterized using genome-wide sequencing technologies is adipogenesis - that is, the differentiation of preadipocytes into mature fat-laden adipocytes. Adi- pogenesis is regulated by a complex series of highly coordinated events that reprogram the genome and activate gene programs that are characteristic for mature adipocytes (Siersbæk and Mandrup 2011).

\section{Cooperativity between Transcription Factors Drives Genomic Programming in Adipogenesis}

So far, most genome-wide insight into adipogenesis originates from studies using mouse and human preadipocyte cell lines, in particular the murine 3T3-L1 preadipocyte cell line (Lefterova et al. 2008; Nielsen et al. 2008; Hamza et al. 2009; Wakabayashi et al. 2009). These preadipocytes can be stimulated to differentiate in vitro using a cocktail of hormonal inducers, which leads to activation of at least two consecutive waves of adipogenic transcription factors. The cocktail initially activates a first wave of early adipogenic transcription factors that ultimately leads to induction of a second wave of transcription factors including the key adipocyte regulators: peroxisome proliferator-activated receptor $\gamma(\mathrm{PPAR} \gamma)$ and CCAAT/enhancer-binding protein $\alpha$ $(\mathrm{C} / \mathrm{EBP} \alpha)($ Siersbæk et al. 2012b).

Several studies have addressed how the chromatin is remodeled and enhancers are established during 3T3-L1 adipogenesis (Mikkelsen et al. 2010; Steger et al. 2010; Siersbæk et al. 2011; Waki et al. 2011; Lee et al. 2013). Genome-wide analyses of the chromatin landscape by DNase-seq have shown that the chromatin template is dramatically remodeled within the first few hours of dif-

\footnotetext{
${ }^{1}$ These two authors contributed equally.

Copyright (C) 2015 Cold Spring Harbor Laboratory Press; all rights reserved; doi: 10.1101/sqb.2015.80.027516 
ferentiation (Siersbæk et al. 2011). Interestingly, a major fraction of early remodeled sites remain open throughout the differentiation process, whereas relatively few sites are remodeled de novo later in adipogenesis. This indicates that a large part of the chromatin signature of mature adipocytes is already established early in the differentiation process before the second wave transcription factors are activated. Once activated, the second-wave transcription factors bind some of the preestablished open chromatin regions suggesting that the early chromatin remodeling is important for establishment of the adipocyte chromatin landscape (Siersbæk and Mandrup 2011). In line with this, several PPAR $\gamma$-binding sites in mature adipocytes are primed by active histone marks, such as lysine-4 methylated histone $\mathrm{H} 3(\mathrm{H} 3 \mathrm{~K} 4 \mathrm{me} 1 / 2)$ and lysine-27 acetylated H3 (H3K27ac), already in preadipocytes (Mikkelsen et al. 2010). These preprogrammed PPAR $\gamma$-binding sites are accessible in multiple cell types, whereas the sites established later in differentiation are not, indicating that late established PPAR $\gamma$ enhancers control the adipocyte-specific functions (Oger et al. 2014).

The early remodeling of the chromatin template is coordinately driven by multiple transcription factors that are organized in hotspots (i.e., putative enhancer sites occupying a large number of transcription factors) (Siersbæk et al. 2011, 2014b). Intriguingly, we and others have recently shown a substantial cross talk between the transcription factors acting at these hotspots. First, knockdown of one of several first-wave factors leads to less recruitment of other first-wave factors to hotspots (Steger et al. 2010; Siersbæk et al. 2011). Here C/EBP $\beta$ may be particularly important, because it occupies most early remodeled sites, and knockdown of this factor has a profound effect on recruitment of other first-wave factors (Siersbæk et al. 2011). Second, the transcription factors occupying these hotspots are less dependent on their consensus DNA-binding motifs compared with regions with a low number of transcription factors bound (Siersbaek et al. 2014a). Furthermore, hotspots are central components of super-enhancers (analogous to stretch-enhancers), which are large clusters of enhancers in close proximity shown to be key drivers of gene programs that define cell identity (Lovén et al. 2013; Parker et al. 2013; Whyte et al. 2013). We and others have shown that the cooperativity between transcription factors is not limited to the individual hotspot/binding site but includes cross talk between individual binding sites within superenhancers (Siersbæk et al. 2014b; Hnisz et al. 2015), which appears to involve 3D interactions by chromosomal looping (Ing-Simmons et al. 2015). Thus, the extensive transcription factor cross talk at the level of hotspots as well as super-enhancers is used to integrate signals from multiple signaling pathways driving the transcriptional reprogramming during early adipogenesis (Fig. 1).

Similar to the studies of early adipogenesis, genomewide studies in mature adipocytes have revealed a highly cooperative action of transcription factors of the second wave. Thus, the key regulators of adipocyte differentiation, C/EBP $\alpha$ and PPAR $\gamma$, bind to many of the same sites

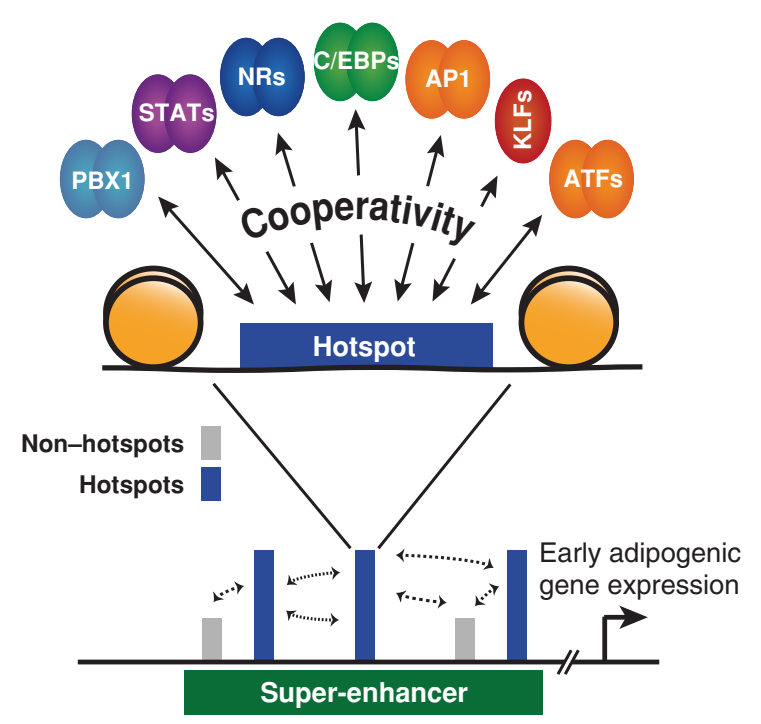

Figure 1. Transcription factor cooperativity in early adipogenic hotspots and super-enhancers. During early adipogenesis, multiple transcription factors cooperate within genomic regions termed transcription factor hotspots in gaining access to DNA and in recruitment of cofactors. These hotspots are central components of super-enhancers that are characterized by multiple closely spaced high-occupancy enhancers among which there appears to be considerable cross talk. The extensive cooperativity at the level of hotspots as well as super-enhancers drives the activation of nearby genes characteristic of the early adipocyte gene program. (Reprinted, with permission, from Siersbaek et al. 2014b.)

(Lefterova et al. 2008; Nielsen et al. 2008), and we have shown an interdependent conservation of $\mathrm{C} / \mathrm{EBP} \alpha$ - and PPAR $\gamma$-binding sites between mouse and human adipocytes (Schmidt et al. 2011). More recently, we formally showed that C/EBP $\alpha$ and PPAR $\gamma$ assist the binding of each other to chromatin at a genome-wide level, and that this is associated with synergistic cofactor recruitment and activation of nearby genes (Madsen et al. 2014). This cooperativity is more pronounced at the level of super-enhancers rather than individual enhancers, and accordingly super-enhancers are more highly enriched near genes synergistically activated by $\mathrm{C} / \mathrm{EBP} \alpha$ and PPAR $\gamma$ (MS Madsen, unpubl.). Given the high degree of cooperativity between C/EBP $\alpha$ and PPAR $\gamma$ in mature adipocytes, we consider it likely that a subset of their target sites serves as late adipogenic hotspots that integrate adipogenic and metabolic signals to stimulate and maintain the adipocyte phenotype.

\section{MODULATING THE GENOMIC PROGRAMMING OF ADIPOCYTES}

\section{Acute Genome-Wide Effects of Rosiglitazone in Mature Adipocytes}

PPAR $\gamma$ is a key driver of adipocyte differentiation (Tontonoz and Spiegelman 2008), but it also plays an important role in fine-tuning the response to external signals in mature adipocytes. One example is the response to 
a class of insulin sensitizing drugs, thiazolidinediones (TZDs), which are high-affinity ligands for PPAR $\gamma$ (Lehmann et al. 1995). TZDs act on multiple tissues and cell types; however, it is well established that PPAR $\gamma$-mediated actions in adipocytes are required for the in vivo systemic insulin sensitizing effects of TZDs (Chao et al. 2000; He et al. 2003). In adipocytes, TZD treatment enhances insulin sensitization by increasing adipogenesis and lipogenesis as well as by inducing genes encoding factors involved in insulin signaling in adipocytes (Ribon et al. 1998; Smith et al. 2001) and in insulin sensitization of other tissues (Maeda et al. 2001; Dutchak et al. 2012). Furthermore, TZDs suppress proinflammatory genes, such as tumor necrosis factor (TNF) (Hofmann et al. 1994), thereby alleviating the negative effects hereof on insulin signaling.

Several studies have addressed long-term effects of TZDs on transcription in adipocytes (Gerhold et al. 2002; Berger et al. 2003; Sears et al. 2007; Wang et al. 2007a; Choi et al. 2010); however, recently we and others used advanced sequencing techniques to characterize the acute genomic and transcriptional response to treatment with the highly potent TZD, rosiglitazone, in 3T3-L1 adipocytes (Haakonsson et al. 2013; Step et al. 2014). Using RNA polymerase II (RNAPII) ChIP-seq (Haakonsson et al. 2013) or GRO-seq (Step et al. 2014) as a measure of ongoing transcription, it was shown that rosiglitazone treatment for $1 \mathrm{~h}$ induces major changes in gene expression. In fact, the Lazar laboratory found prominent changes in transcription within $10 \mathrm{~min}$ of rosiglitazone treatment of 3T3-L1 adipocytes (Step et al. 2014). As expected, we found that genes activated by rosiglitazone are induced during adipocyte differentiation and belong to lipid metabolizing processes (Haakonsson et al. 2013), which is in accordance with previous studies of long-term effects of rosiglitazone (Wang et al. 2007a). Importantly, the acute rosiglitazone-mediated changes in transcription correlate well with changes in gene expression in inguinal white adipose tissues treated with rosiglitazone (Ohno et al. 2012; Step et al. 2014), suggesting that these acute changes are physiologically relevant.

In addition to the acute changes in transcription, we investigated how acute rosiglitazone treatment affects binding of the master adipocyte transcriptional regulators PPAR $\gamma$ and $\mathrm{C} / \mathrm{EBP} \alpha$ as well as the activity of adipocyte enhancers, as determined by the coactivators, mediator complex subunit 1 (MED1) and CREB-binding protein (CBP) (Haakonsson et al. 2013). In contrast to what has been observed for many other nuclear receptors (Kininis et al. 2007; Wang et al. 2007b; Boergesen et al. 2012), the genome-wide binding pattern of PPAR $\gamma$ is not dramatically changed in response to acute rosiglitazone treatment. Nevertheless, PPAR $\gamma$ binding to many preexisting sites is significantly increased upon rosiglitazone administration. This increase in PPAR $\gamma$ binding correlates with increased occupancy of MED1 indicating that these putative enhancers become more active. Furthermore, both PPAR $\gamma$ and MED1 binding are more dramatically induced at MED1 super-enhancers compared with individual enhancers upon rosiglitazone treatment, and these super-enhancers are more highly enriched near rosiglitazone-induced genes (AK Haakonsson, unpubl.). In line with our results, more recent data show that PPAR $\gamma$ directly mediates the induction of enhancer RNAs (eRNAs) and is required for enhancer activation upon rosiglitazone treatment of 3T3-L1 adipocytes (Step et al. 2014). Consistent with this, PPAR $\gamma$, but not $\mathrm{C} / \mathrm{EBP} \alpha$, binding correlates well with gene activation by rosiglitazone (Haakonsson et al. 2013; Step et al. 2014; Soccio et al. 2015). Using loss-of-function adipocyte models we confirmed that the expression of genes activated by rosiglitazone was highly dependent on PPAR $\gamma$, whereas genes repressed by TZDs are more dependent on $\mathrm{C} / \mathrm{EBP} \alpha$. In this regard, previous investigations from the Farmer group indicated a role for $\mathrm{C} / \mathrm{EBP} \alpha$ in the repression of adipocyte genes in mature adipocytes (Vernochet et al. 2009). Interestingly, recent work from the Lazar group showed that rosiglitazone acutely represses gene transcription in mature adipocytes by redistributing coactivators from other transcription factors, such as $\mathrm{C} / \mathrm{EBP}$ and AP-1 factors, to PPAR $\gamma$-activated enhancers (Step et al. 2014). This is in line with other recent genomewide studies of nuclear receptor-mediated transcriptional repression (He et al. 2012; Guertin et al. 2014) and may mechanistically involve squelching of a limited amount of cofactors in the cell (Meyer et al. 1989; Kamei et al. 1996).

\section{Long-Term Rosiglitazone-Mediated Browning of Human Adipocytes}

It is well established that long-term exposure to TZDs promotes the formation of functional brown-like adipocytes in rodent and human adipocyte cultures and white adipose tissue (Digby et al. 1998; Fukui et al. 2000; Bogacka et al. 2005; Elabd et al. 2009; Ishibashi and Seale 2010; Petrovic et al. 2010; Wu et al. 2012). Such brownlike adipocytes have been termed brown-in-white (i.e., brite) (Petrovic et al. 2010) and may be similar to beige adipocytes (Ishibashi and Seale 2010; Wu et al. 2012). It has been suggested that TZDs operate by directly activating PPAR $\gamma$ at regions near brite adipocyte genes (Sears et al. 1996); however, we and others have shown that browning is not induced immediately upon TZD treatment of adipocytes (Petrovic et al. 2010; Haakonsson et al. 2013), suggesting that additional indirect effectors are required for full activation and maintenance of a brite adipocyte gene program.

We recently applied sequencing technologies to characterize the genomic programming events underlying the formation of functional human brown-like adipocytes (Loft et al. 2015). As a model system we used human multipotent adipose-derived stem (hMADS) cells, which can be stimulated to transdifferentiate from white-to-brite adipocytes by prolonged rosiglitazone treatment (Elabd et al. 2009). We found that the browning process activates a comprehensive gene program that reflects the functional properties of brite adipocytes (i.e., increased mitochondrial respiration and fatty acid oxidation). Interestingly, once the brite adipocyte gene program is established, it 
can be maintained independently of continued rosiglitazone stimulation, thereby supporting the idea that additional "stabilizing" effectors are induced during the browning process, and that these are required for activation and stabilization of the brite adipocyte gene program.

To identify such effectors we investigated the reprogramming of PPAR $\gamma$-binding sites during the browning process. We found that only a smaller subset of PPAR $\gamma$ binding sites is reprogrammed during browning and showed that gain of PPAR $\gamma$ at these sites correlates with a gain in enhancer activity and increase in expression of nearby genes. This indicates that PPAR $\gamma$ acts in a highly site-selective manner to drive the browning process. This is in line with our results from primary ex vivo differentiated mouse white and brown fat cells showing that PPAR $\gamma$ binding differs only at a subset of sites between adipocyte subtypes (Siersbæk et al. 2012a).

Interestingly, the TZD-mediated reprogramming of PPAR $\gamma$ binding in human adipocytes results in the formation of a set of PPAR $\gamma$ super-enhancers that are markedly induced upon browning (Fig. 2). These brite-selective PPAR $\gamma$ super-enhancers are highly enriched near brite adipocyte genes encoding key metabolic regulators involved in fatty acid metabolism and $\beta$-oxidation as well as transcriptional regulators. Because super-enhancers previously have been shown to associate with lineagedetermining transcription factors (Whyte et al. 2013), we identified putative browning factors based on their association with brite-selective PPAR $\gamma$ super-enhancers. From these analyses, the Krüppel-like factor 11 (KLF11) was revealed as a novel PPAR $\gamma$ target gene in human adipocytes that is induced during the browning process. Using a combination of ChIP-seq and loss- and gain-offunction studies we showed that KLF11 is a direct transcriptional activator of the brite adipocyte gene program and is required for acquisition of the brown phenotype.
Thus, KLF11 appears to act as a "stabilizing" browning effector, thereby serving as a link between acute rosiglitazone stimulation and maintenance of the brite adipocyte phenotype. KLF11 might also be involved in mediating other browning responses, because KLF11 expression can be induced in brite hMADS adipocytes as well as in primary human adipocytes from the supraclavicular brownish depot by alternative thermogenic stimuli, such as cooling and $\beta$-adrenergic stimulation (Loft et al. 2015; A Loft, unpubl.). Furthermore, we found that KLF11 expression is induced in abdominal subcutaneous adipose tissue of human type II diabetic subjects treated with rosiglitazone for $3 \mathrm{mo}$, which is paralleled by an induction of uncoupling protien 1 (UCP1) expression in some of these patients. This indicates that TZDs, in line with previous studies (Bogacka et al. 2005), can induce browning of human subcutaneous adipose depots and that this includes activation of the KLF11 gene (Loft et al. 2015).

Cumulatively, our data show a comprehensive change in the genomic programming in response to rosiglitazoneinduced browning of human adipocytes and show that KLF11 plays an important role in this process. It would be surprising if the change in genomic programming during adipocyte browning is driven by a single or a few transcription factors. We suggest that rosiglitazone stimulation of mature human adipocytes leads to an acute, but partial activation of brite adipocyte gene expression, including induction of transcriptional browning effectors that accumulate over time. These browning effectors subsequently cooperate with PPAR $\gamma$ and general adipocyte transcription factors in brite adipocyte hotspots to modify the programming of the genome and form stabilized (late) brite-selective super-enhancers, thereby further promoting and maintaining the brite adipocyte gene program (Fig. 3). KLF11 constitutes one of only a few putative

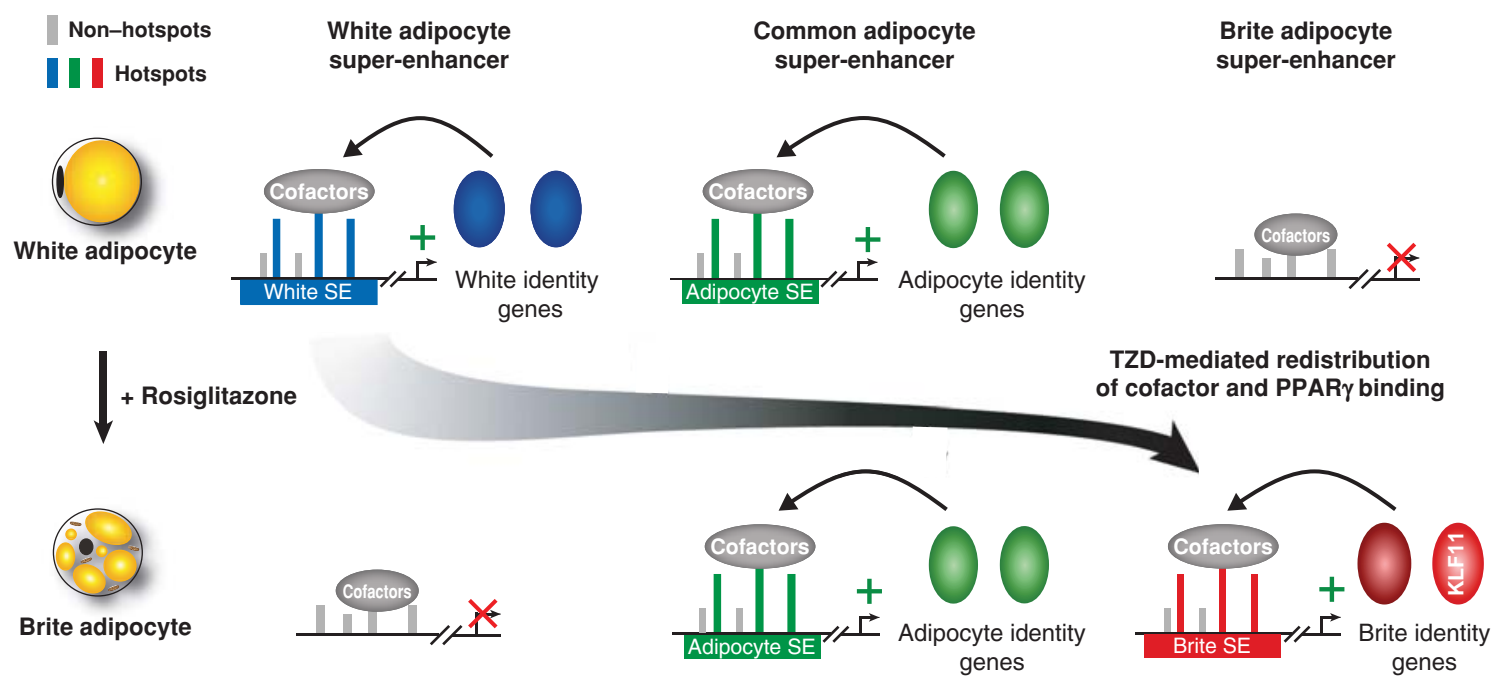

Figure 2. Browning-induced reprogramming of super-enhancers in human adipocytes. Browning of human white adipocytes with rosiglitazone leads to a shift in the super-enhancer (SE) composition with redistribution of the transcriptional machinery from whiteselective SE to form brite-selective SE. Consequently, the white adipocyte gene program is suppressed upon rosiglitazone treatment, and a brite adipocyte gene program is turned on, which leads to the expression of genes encoding browning factors as well as key metabolic genes that define the brite adipocyte. TZD, thiazolidinedione. 


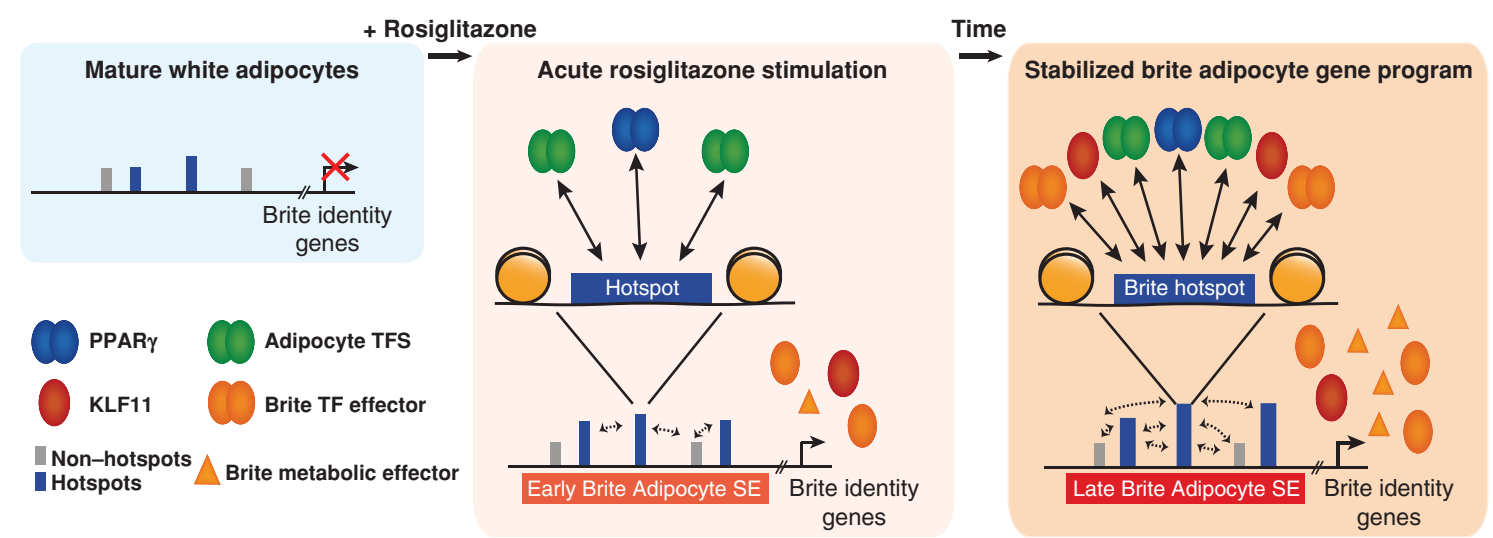

Figure 3. Model depicting how stabilizing effectors maintain the browning-induced gene program. Rosiglitazone treatment of human white adipocytes leads to an acute stimulation and redistribution of PPAR $\gamma$ that subsequently cooperate with other adipocyte transcription factors (TFs) within hotspots to partially activate brite adipocyte genes. This includes transcriptional browning effectors, such as KLF11, which accumulate progressively over time. These browning factors cooperate with PPAR $\gamma$ and other adipocyte TFs in brite adipocyte hotspots to further modify the genomic program and form "stable" late brite-selective super-enhancers (SE). Ultimately, the concerted action of PPAR $\gamma$ and the browning effectors leads to full activation of the brite adipocyte gene program that can be maintained without sustained rosiglitazone stimulation.

browning effectors identified. Motif analyses in cell type-specific PPAR $\gamma$-binding sites in brown versus white mouse adipocytes recently identified early B-cell factor-2 (Ebf2) as a brown adipocyte-enriched factor that facilitates binding of PPAR $\gamma$ and cooperate with PPAR $\gamma$ to induce brown adipocyte-specific genes (Rajakumari et al. 2013). Future studies should investigate the cooperativity between transcription factors to unravel how browning-selective enhancers are established and to understand the mechanisms underlying activation of a brite adipocyte program.

\section{TNF-Induced Adipocyte Inflammation}

Inflammatory signals constitute other important modulators of adipocyte function. Obesity and systemic insulin resistance are associated with chronic inflammation in the adipose tissue, which appears to promote adipocyte dysfunction (Guilherme et al. 2008). This is recapitulated in cell culture studies where TNF, which in vivo is secreted mainly from macrophages, is antiadipogenic and promotes insulin resistance. However, inflammatory signals in the adipose tissue have also been reported to play an important role in healthy adipose expansion during early stages of obesity (Wernstedt Asterholm et al. 2014) as well as in browning of adipose tissue (Petruzzelli et al. 2014; Qiu et al. 2014; Lee et al. 2015).

Although genome-wide studies have reported that obesity and systemic insulin resistance are associated with an inflammatory gene signature in the adipose tissue in mice (Weisberg et al. 2003; Qi et al. 2009) as well as in humans (Lee et al. 2005; Tam et al. 2011; Arner et al. 2012), it is still not well understood how the genomic programming of the adipocytes is changed to drive these changes in gene expression. However, the Lodish/Fraenkel laboratories recently compared the changes in the transcriptome of 3T3-L1 adipocytes in response to different insulin desen- sitizers with the changes in the adipose tissue transcriptome observed in response to diet-induced obesity. These studies revealed that the gene signatures of 3T3-L1 adipocytes exposed to TNF, hypoxia, or the combination of these more closely mimic the gene signature of insulin resistance in vivo, compared with the gene signature of 3T3-L1 adipocytes exposed to high insulin or dexamethasone (Lo et al. 2013). In line with their previous work (Ruan et al. 2002), they observed a pronounced repression of adipocyte genes by both TNF in culture and by high-fat feeding of mice (Lo et al. 2013). Furthermore, using DNase-seq profiling and motif analysis of the DNA regions undergoing chromatin remodeling upon TNF stimulation, $\mathrm{C} / \mathrm{EBP} \beta$ was identified as an important positive mediator of the TNF-induced gene program associated with insulin resistance. A similar approach was used by the Rosen laboratory to study the transcriptional mechanisms underlying dexamethasone- and TNF-induced insulin resistance in 3T3-L1 adipocytes (Kang et al. 2015). Focusing on the enhancers and genes activated by both treatments, the authors identified a surprising role for glucocorticoid receptor (GR) and vitamin D receptor (VDR) not only in glucocorticoid-induced insulin resistance but also in TNF-induced insulin resistance (Kang et al. 2015). Whereas these two studies used genome-wide profiling of epigenetic events to identify novel factors involved in gene activation following TNF treatment, we recently reported a study focusing on the mechanisms underlying the repression of adipocyte genes by TNF.

To identify TNF-regulated genes, we performed total RNA-seq in human Simpson-Golabi-Behmel syndrome (SGBS) adipocytes following a 90-min TNF-stimulation and used our recently developed computational tool, iRNA-seq, to assess changes in transcriptional activity based on intron reads from these data (Madsen et al. 2015). This allowed us to detect a pronounced acute repression of the transcriptional activity of adipocyte cell identity genes as well as acute induction of inflammatory 
genes (Schmidt et al. 2015). We showed that this correlates with TNF-induced changes in enhancer activity as evidenced by redistribution of the cofactors, MED1 and bromodomain-containing protein 4 (BRD4), RNAPII, and enhancer transcription. Furthermore, we showed that the TNF-induced modifications of the adipocyte transcriptional program require the major transactivating subunit of nuclear factor kappa-light-chain-enhancer of activated B cells (NF- $\mathrm{B})$, v-rel avian reticuloendotheliosis viral oncogene homolog A (RELA). This extends previous reports on the requirement of intact nuclear factor of kappa light polypeptide gene enhancer in B-cells inhibitor, alpha $(\mathrm{I} \kappa \mathrm{B} \alpha)$ signaling for repression of adipocyte gene expression in mouse 3T3-L1 adipocytes (Ruan et al. 2002; Gao et al. 2006). The Ye laboratory suggested that $\mathrm{I} \kappa \mathrm{B} \alpha$ signaling facilitates nuclear translocation of the corepressor histone deacetylase 3 (HDAC3) to mediate repression of PPAR $\gamma$-activated adipocyte genes (Ruan et al. 2002; Gao et al. 2006), but we did not observe any changes in nuclear localization of HDAC3 (BD Larsen, unpubl.) suggesting a different mechanism of repression in human adipocytes.

Interestingly, enhancers repressed by TNF are generally devoid of RELA binding (Schmidt et al. 2015), suggesting that RELA-induced repression is indirect and caused by redistribution, possibly squelching, of a limited amount of cofactors to newly activated enhancers (Meyer et al. 1989; Kamei et al. 1996; He et al. 2012; Guertin et al. 2014; Step et al. 2014). Importantly however, such a mechanism does not explain the fact that only a small subset of active enhancers and genes are repressed. By analyzing the characteristics of the repressed enhancers we discovered that redistribution occurs predominantly at enhancers with high-cofactor occupancies, thereby predominantly affecting super-enhancers and their associated cell identity genes (Schmidt et al. 2015). Thus, the intrinsic sensitivity of super-enhancers to general perturbations (Lovén et al. 2013; Whyte et al. 2013) appears to explain how cofactor redistribution can elicit repression of a specific subset of active enhancers and genes. In support hereof, we developed models based on high-cofactor binding in unstimulated cells and low RELA binding in stimulated cells that can predict which enhancers and genes are repressed by TNF in adipocytes with high accuracy. The accuracy for this prediction is as high as the accuracy with which RELA binding can predict enhancer and gene activation (Schmidt et al. 2015). In further support of an indirect mechanism of repression and a competition between high-occupancy enhancers for a limited amount of cofactors, we showed that TNF-repressed genes also display increased sensitivity to repression by the chemical inhibitor of BRD4, JQ1, compared with constitutive genes. Interestingly, in TNF-stimulated adipocytes JQ1 did not further affect adipocyte cell identity genes repressed by TNF, but led to selective suppression of TNF-induced inflammatory genes associated with de novo established super-enhancers. These results are in line with recent studies demonstrating that JQ1 selectively targets TNF-induced inflammatory super-enhancers in endothelial cells and thereby reduces TNF-induced atherogenic endothelial responses in vitro and atherosclerosis in vivo (Brown et al. 2014).

Importantly, our observations regarding cofactor redistribution and our models for prediction of TNF-induced repression of enhancers and associated genes are applicable to other cell types, suggesting that RELA-mediated cofactor redistribution from super-enhancers is a general mechanism underlying repression of cell identity genes by TNF (Fig. 4). Thus, whereas TNF induces common inflammatory gene programs in different cell types, repression appears to be highly cell type-specific, because it relies mainly on cofactor redistribution from superenhancers associated with cell identity genes. In the context of acute inflammation this may serve to redirect translational capacity to newly synthesized inflammatory mRNAs, thereby optimizing the inflammatory response and defense (Fig. 5). However, in the context of chronic low-grade inflammation this may contribute to repression of cell identity genes as observed in adipose tissue of obese subjects. In line with this, we showed that several

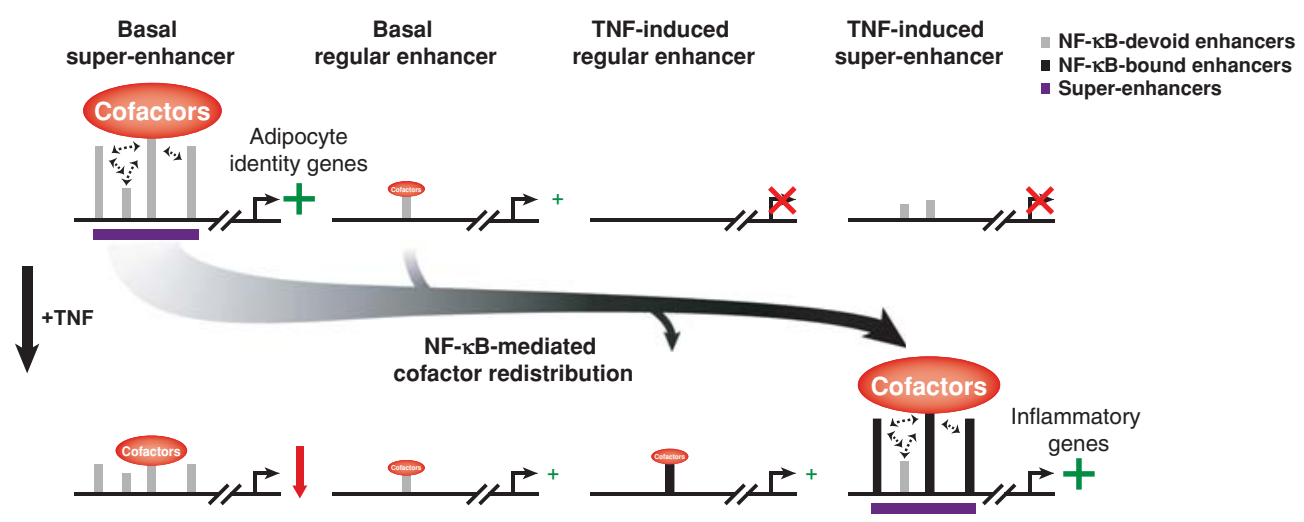

Figure 4. Transcriptional repression by NF-кB-mediated cofactor redistribution from high-occupancy enhancers. Following tumor necrosis factor (TNF) treatment, cofactors redistribute to NF-кB-activated enhancers, in particular super-enhancers, near inflammatory genes. This redistribution occurs predominantly from the adipocyte basal super-enhancers that do not recruit RELA, thereby leading to specific repression of adipocyte genes associated with these super-enhancers. (Reprinted, with permission, from Schmidt et al. 2015, Cold Spring Harbor Laboratory Press.) 

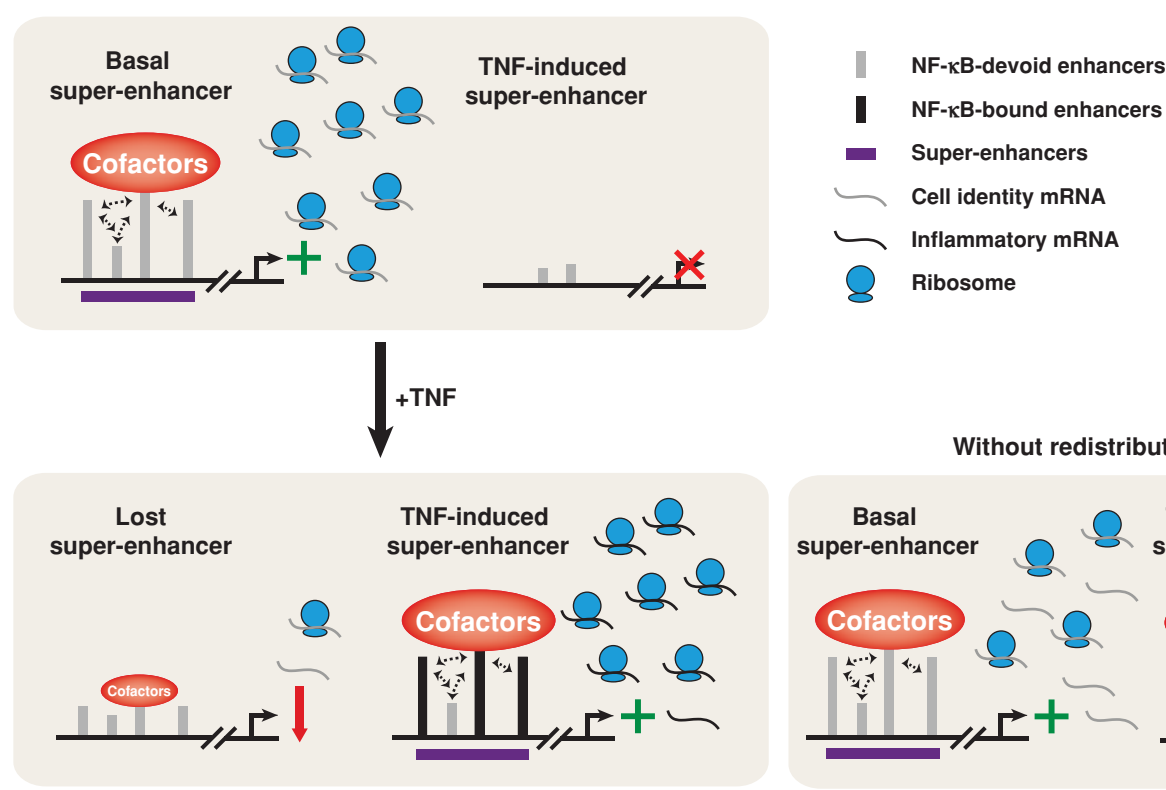

Figure 5. Model depicting the principle of super-enhancer-guided redirection of translational capacity from cell identify to inflammatory mRNAs. In the unstimulated state considerable translational capacity is dedicated to mRNAs encoded from super-enhancerassociated cell identify genes serving to maintain the specialized function of the particular cell type (top). Upon inflammatory stimuli, cofactors are redistributed from super-enhancers leading to a general repression of cell identify genes. Thus, newly synthesized inflammatory mRNAs gain translational capacity thereby optimizing the inflammatory response (bottom left). In the hypothetical absence of cofactor redistribution and repression of cell identity genes, inflammatory mRNAs would be competing with cell identify mRNAs for a limiting amount of ribosomes in the cell, thereby resulting in a less efficient inflammatory defense (bottom right).

transcriptional activators of adipocyte differentiation and function $(\mathrm{PPAR} \gamma, \mathrm{C} / \mathrm{EBP} \alpha$, retinoid $\mathrm{X}$ receptor $\gamma[\mathrm{RXR} \gamma]$, transducin-like enhancer of split 3 [TLE3], and sterol regulatory element-binding transcription factor 1 [SREBF1]), the transcription of which is acutely repressed by TNF, also display a sustained (24-h) repression at the mRNA level. The eventual decrease in the protein levels of these regulators is, as previously described for PPAR $\gamma$ (Zhang et al. 1996; Tang et al. 2006; Guilherme et al. 2008), a likely explanation for the sustained chronic repression of adipocyte gene expression and function by TNF.

We propose that cofactor redistribution selectively from high-occupancy enhancers is a general mechanism contributing to transcriptional repression associated with activation of signal-dependent transcription factors. We further speculate that this mechanism is also involved in gene repression during other transitions like cellular differentiation, which would be consistent with the notion that most mammalian transcription factors are activating (Hurst et al. 2014).

\section{CONCLUDING REMARKS}

Collectively, our work shows how the genomic landscape of adipocytes can be modulated by external signals that impact on the activity of PPAR $\gamma$ and other adipocyte transcriptional regulators. Furthermore, it outlines how the organization of the genome with clustering of individual enhancers into super-enhancers could allow cells to efficiently switch between specialized gene programs while maintaining expression of vital housekeeping genes. Thus, super-enhancers of different gene programs compete for a limited amount of cofactors, and when the balance is shifted by an external signal, the fact that the transcription factors driving specialized gene programs themselves are often under super-enhancer control contributes to an amplifying feedforward mechanism.

\section{ACKNOWLEDGMENTS}

We thank members of the Mandrup Laboratory who were key contributors to the work discussed here, particularly Rasmus Siersbæk, Ronni Nielsen, Maria Stahl Madsen, Anders Kristian Haakonsson, Bjørk Ditlev Larsen, Isabel Forss, and Majken Siersbæk. This work was supported by grants from the Danish Independent Research Council Natural Sciences, the Novo Nordisk Foundation, the Lundbeck Foundation, the Danish Diabetes Academy supported by the Novo Nordisk Foundation, and the VILLUM Foundation to the VILLUM Center for Bioanalytical Sciences at the University of Southern Denmark.

\section{REFERENCES}

Arner E, Mejhert N, Kulyté A, Balwierz PJ, Pachkov M, Cormont $\mathrm{M}$, Lorente-Cebrián $\mathrm{S}$, Ehrlund A, Laurencikiene J, Hedén P, et al. 2012. Adipose tissue microRNAs as regulators of CCL2 production in human obesity. Diabetes 61: 19861993.

Berger JP, Petro AE, Macnaul KL, Kelly LJ, Zhang BB, Richards K, Elbrecht A, Johnson BA, Zhou G, Doebber 
TW, et al. 2003. Distinct properties and advantages of a novel peroxisome proliferator-activated protein $[\gamma]$ selective modulator. Mol Endocrinol 17: 662-676.

Boergesen M, Pedersen TA, Gross B, van Heeringen SJ, Hagenbeek D, Bindesbøll C, Caron S, Lalloyer F, Steffensen KR, Nebb HI, et al. 2012. Genome-wide profiling of liver X receptor, retinoid X receptor, and peroxisome proliferator-activated receptor $\alpha$ in mouse liver reveals extensive sharing of binding sites. Mol Cell Biol 32: 852-867.

Bogacka I, Xie H, Bray GA, Smith SR. 2005. Pioglitazone induces mitochondrial biogenesis in human subcutaneous adipose tissue in vivo. Diabetes 54: 1392-1399.

Brown JD, Lin CY, Duan Q, Griffin G, Federation AJ, Paranal RM, Bair S, Newton G, Lichtman AH, Kung AL, et al. 2014. NF- $\mathrm{kB}$ directs dynamic super-enhancer formation in inflammation and atherogenesis. Mol Cell 56: 219-231.

Chao L, Marcus-Samuels B, Mason MM, Moitra J, Vinson C, Arioglu E, Gavrilova O, Reitman ML. 2000. Adipose tissue is required for the antidiabetic, but not for the hypolipidemic, effect of thiazolidinediones. J Clin Invest 106: 1221-1228.

Choi JH, Banks AS, Estall JL, Kajimura S, Boström P, Laznik D, Ruas JL, Chalmers MJ, Kamenecka TM, Blüher M, et al. 2010. Anti-diabetic drugs inhibit obesity-linked phosphorylation of PPAR $\gamma$ by Cdk5. Nature 466: 451-456.

Crawford GE, Holt IE, Whittle J, Webb BD, Tai D, Davis S, Margulies EH, Chen Y, Bernat JA, Ginsburg D, et al. 2006. Genome-wide mapping of DNase hypersensitive sites using massively parallel signature sequencing (MPSS). Genome Res 16: 123-131.

Digby JE, Montague CT, Sewter CP, Sanders L, Wilkison WO, O'Rahilly S, Prins JB. 1998. Thiazolidinedione exposure increases the expression of uncoupling protein 1 in cultured human preadipocytes. Diabetes 47: 138-141.

Dutchak PA, Katafuchi T, Bookout AL, Choi JH, Yu RT, Mangelsdorf DJ, Kliewer SA. 2012. Fibroblast growth factor-21 regulates PPAR $\gamma$ activity and the antidiabetic actions of thiazolidinediones. Cell 148: 556-567.

Elabd C, Chiellini C, Carmona M, Galitzky J, Cochet O, Petersen R, Pénicaud L, Kristiansen K, Bouloumié A, Casteilla L, et al. 2009. Human multipotent adipose-derived stem cells differentiate into functional brown adipocytes. Stem Cells 27: 2753-2760.

Fukui Y, Masui S, Osada S, Umesono K, Motojima K. 2000. A new thiazolidinedione, NC-2100, which is a weak PPAR- $\gamma$ activator, exhibits potent antidiabetic effects and induces uncoupling protein 1 in white adipose tissue of KKAy obese mice. Diabetes 49: 759-767.

Gao Z, He Q, Peng B, Chiao PJ, Ye J. 2006. Regulation of nuclear translocation of HDAC3 by IкB $\alpha$ is required for tumor necrosis factor inhibition of peroxisome proliferator-activated receptor $\gamma$ function. J Biol Chem 281: 4540-4547.

Gerhold DL, Liu F, Jiang G, Li Z, Xu J, Lu M, Sachs JR, Bagchi A, Fridman A, Holder DJ, et al. 2002. Gene expression profile of adipocyte differentiation and its regulation by peroxisome proliferator-activated receptor- $\gamma$ agonists. Endocrinology 143: $2106-2118$.

Gerstein MB, Kundaje A, Hariharan M, Landt SG, Yan K-K, Cheng C, Mu XJ, Khurana E, Rozowsky J, Alexander R, et al. 2012. Architecture of the human regulatory network derived from ENCODE data. Nature 489: 91-100.

Guertin MJ, Zhang X, Coonrod SA, Hager GL. 2014. Transient estrogen receptor binding and p300 redistribution support a squelching mechanism for estradiol-repressed genes. Mol Endocrinol 28: $1522-1533$.

Guilherme A, Virbasius JV, Puri V, Czech MP. 2008. Adipocyte dysfunctions linking obesity to insulin resistance and type 2 diabetes. Nat Rev Mol Cell Biol 9: 367-377.

Haakonsson AK, Stahl Madsen M, Nielsen R, Sandelin A, Mandrup S. 2013. Acute genome-wide effects of rosiglitazone on PPAR $\gamma$ transcriptional networks in adipocytes. Mol Endocrinol 27: $1536-1549$.

Hamza MS, Pott S, Vega VB, Thomsen JS, Kandhadayar GS, Ng PW, Chiu KP, Pettersson S, Wei CL, Ruan Y, et al. 2009. De- novo identification of PPAR $\gamma / \mathrm{RXR}$ binding sites and direct targets during adipogenesis. PLoS One 4: e4907.

He W, Barak Y, Hevener A, Olson P, Liao D, Le J, Nelson M, Ong E, Olefsky JM, Evans RM. 2003. Adipose-specific peroxisome proliferator-activated receptor $\gamma$ knockout causes insulin resistance in fat and liver but not in muscle. Proc Natl Acad Sci 100: 15712-15717.

$\mathrm{He} \mathrm{HH}$, Meyer CA, Chen MW, Jordan VC, Brown M, Liu XS. 2012. Differential DNase I hypersensitivity reveals factor-dependent chromatin dynamics. Genome Res 22: 1015-1025.

Hnisz D, Schuijers J, Lin CY, Weintraub AS, Abraham BJ, Lee TI, Bradner JE, Young RA. 2015. Convergence of developmental and oncogenic signaling pathways at transcriptional super-enhancers. Mol Cell 58: 362-370.

Hofmann C, Lorenz K, Braithwaite SS, Colca JR, Palazuk BJ, Hotamisligil GS, Spiegelman BM. 1994. Altered gene expression for tumor necrosis factor- $\alpha$ and its receptors during drug and dietary modulation of insulin resistance. Endocrinology 134: $264-270$.

Hurst LD, Sachenkova O, Daub C, Forrest AR, Huminiecki L, FANTOM consortium. 2014. A simple metric of promoter architecture robustly predicts expression breadth of human genes suggesting that most transcription factors are positive regulators. Genome Biol 15: 413.

Ing-Simmons E, Seitan VC, Faure AJ, Flicek P, Carroll T, Dekker J, Fisher AG, Lenhard B, Merkenschlager M. 2015. Spatial enhancer clustering and regulation of enhancer-proximal genes by cohesin. Genome Res 25: 504-513.

Ishibashi J, Seale P. 2010. Medicine. Beige can be slimming. Science 328: 1113-1114.

Kamei Y, Xu L, Heinzel T, Torchia J, Kurokawa R, Gloss B, Lin SC, Heyman RA, Rose DW, Glass CK, et al. 1996. A CBP integrator complex mediates transcriptional activation and AP-1 inhibition by nuclear receptors. Cell 85: 403-414.

Kang S, Tsai LT, Zhou Y, Evertts A, Xu S, Griffin MJ, Issner R, Whitton HJ, Garcia BA, Epstein CB, et al. 2015. Identification of nuclear hormone receptor pathways causing insulin resistance by transcriptional and epigenomic analysis. Nat Cell Biol 17: 44-56.

Kininis M, Chen BS, Diehl AG, Isaacs GD, Zhang T, Siepel AC, Clark AG, Kraus WL. 2007. Genomic analyses of transcription factor binding, histone acetylation, and gene expression reveal mechanistically distinct classes of estrogen-regulated promoters. Mol Cell Biol 27: 5090-5104.

Lee YH, Nair S, Rousseau E, Allison DB, Page GP, Tataranni PA, Bogardus C, Permana PA. 2005. Microarray profiling of isolated abdominal subcutaneous adipocytes from obese vs non-obese Pima Indians: Increased expression of inflammation-related genes. Diabetologia 48: 1776-1783.

Lee JE, Wang C, Xu S, Cho Y-W, Wang L, Feng X, Baldridge A, Sartorelli V, Zhuang L, Peng W, et al. 2013. H3K4 mono- and di-methyltransferase MLL4 is required for enhancer activation during cell differentiation. Elife 2: e01503.

Lee M-W, Odegaard JI, Mukundan L, Qiu Y, Molofsky AB, Nussbaum JC, Yun K, Locksley RM, Chawla A. 2015. Activated type 2 innate lymphoid cells regulate beige fat biogenesis. Cell 160: 74-87.

Lefterova MI, Zhang Y, Steger DJ, Schupp M, Schug J, Cristancho A, Feng D, Zhuo D, Stoeckert CJ Jr, Liu XS, et al. 2008. PPAR $y$ and C/EBP factors orchestrate adipocyte biology via adjacent binding on a genome-wide scale. Genes Dev 22: 2941-2952.

Lehmann JM, Moore LB, Smith-Oliver TA, Wilkison WO, Willson TM, Kliewer SA. 1995. An antidiabetic thiazolidinedione is a high affinity ligand for peroxisome proliferator-activated receptor $\gamma$ (PPAR $\gamma)$. J Biol Chem 270: 12953-12956.

Lo KA, Labadorf A, Kennedy NJ, Han MS, Yap YS, Matthews B, Xin X, Sun L, Davis RJ, Lodish HF, et al. 2013. Analysis of in vitro insulin-resistance models and their physiological relevance to in vivo diet-induced adipose insulin resistance. Cell Rep 5: 259-270.

Loft A, Forss I, Siersbæk MS, Schmidt SF, Larsen A-S, Madsen JGS, Pisani DF, Nielsen R, Aagaard MM, Mathison A, et al. 
2015. Browning of human adipocytes requires KLF11 and reprogramming of PPARy super-enhancers. Genes Dev 29: $7-22$.

Lovén J, Hoke HA, Lin CY, Lau A, Orlando DA, Vakoc CR, Bradner JE, Lee TI, Young RA. 2013. Selective inhibition of tumor oncogenes by disruption of super-enhancers. Cell 153: $320-334$.

Madsen MS, Siersbaek R, Boergesen M, Nielsen R, Mandrup S. 2014. Peroxisome proliferator-activated receptor $\gamma$ and $\mathrm{C} /$ EBP $\alpha$ synergistically activate key metabolic adipocyte genes by assisted loading. Mol Cell Biol 34: 939-954.

Madsen JGS, Schmidt SF, Larsen BD, Loft A, Nielsen R, Mandrup S. 2015. iRNA-seq: Computational method for genomewide assessment of acute transcriptional regulation from total RNA-seq data. Nucleic Acids Res 43: e40.

Maeda N, Takahashi M, Funahashi T, Kihara S, Nishizawa H, Kishida K, Nagaretani H, Matsuda M, Komuro R, Ouchi N, et al. 2001. PPAR $y$ ligands increase expression and plasma concentrations of adiponectin, an adipose-derived protein. Diabetes 50: 2094-2099.

Meyer ME, Gronemeyer H, Turcotte B, Bocquel MT, Tasset D, Chambon P. 1989. Steroid hormone receptors compete for factors that mediate their enhancer function. Cell 57: 433-442.

Mikkelsen TS, Xu Z, Zhang X, Wang L, Gimble JM, Lander ES, Rosen ED. 2010. Comparative epigenomic analysis of murine and human adipogenesis. Cell 143: 156-169.

Nielsen R, Pedersen TA, Hagenbeek D, Moulos P, Siersbaek R, Megens E, Denissov S, Børgesen M, Francoijs K-J, Mandrup $\mathrm{S}$, et al. 2008. Genome-wide profiling of PPAR $\gamma:$ RXR and RNA polymerase II occupancy reveals temporal activation of distinct metabolic pathways and changes in RXR dimer composition during adipogenesis. Genes Dev 22: 2953-2967.

Oger F, Dubois-Chevalier J, Gheeraert C, Avner S, Durand E, Froguel P, Salbert G, Staels B, Lefebvre P, Eeckhoute J. 2014. Peroxisome proliferator-activated receptor $\gamma$ regulates genes involved in insulin/insulin-like growth factor signaling and lipid metabolism during adipogenesis through functionally distinct enhancer classes. J Biol Chem 289: 708-722.

Ohno H, Shinoda K, Spiegelman BM, Kajimura S. 2012. PPAR $y$ agonists induce a white-to-brown fat conversion through stabilization of PRDM16 protein. Cell Metab 15: $395-404$.

Parker SCJ, Stitzel ML, Taylor DL, Orozco JM, Erdos MR, Akiyama JA, van Bueren KL, Chines PS, Narisu N, NISC Comparative Sequencing Program, et al. 2013. Chromatin stretch enhancer states drive cell-specific gene regulation and harbor human disease risk variants. Proc Natl Acad Sci 110: $17921-17926$

Petrovic N, Walden TB, Shabalina IG, Timmons JA, Cannon B, Nedergaard J. 2010. Chronic peroxisome proliferator-activated receptor $\gamma(\operatorname{PPAR} \gamma)$ activation of epididymally derived white adipocyte cultures reveals a population of thermogenically competent, UCP1-containing adipocytes molecularly distinct from classic brown adipocytes. $J$ Biol Chem 285: $7153-7164$.

Petruzzelli M, Schweiger M, Schreiber R, Campos-Olivas R, Tsoli M, Allen J, Swarbrick M, Rose-John S, Rincon M, Robertson $G$, et al. 2014. A switch from white to brown fat increases energy expenditure in cancer-associated cachexia. Cell Metab 20: 433-447.

Qi L, Saberi M, Zmuda E, Wang Y, Altarejos J, Zhang X, Dentin R, Hedrick S, Bandyopadhyay G, Hai T, et al. 2009. Adipocyte CREB promotes insulin resistance in obesity. Cell Metab 9: $277-286$.

Qiu Y, Nguyen KD, Odegaard JI, Cui X, Tian X, Locksley RM, Palmiter RD, Chawla A. 2014. Eosinophils and type 2 cytokine signaling in macrophages orchestrate development of functional beige fat. Cell 157: 1292-1308.

Rajakumari S, Wu J, Ishibashi J, Lim HW, Giang AH, Won KJ, Reed RR, Seale P. 2013. EBF2 determines and maintains brown adipocyte identity. Cell Metab 17: 562-574.

Ribon V, Johnson JH, Camp HS, Saltiel AR. 1998. Thiazolidinediones and insulin resistance: Peroxisome proliferator acti- vated receptor $\gamma$ activation stimulates expression of the CAP gene. Proc Natl Acad Sci 95: 14751-14756.

Roadmap Epigenomics Consortium, Kundaje A, Meuleman W, Ernst J, Bilenky M, Yen A, Heravi-Moussavi A, Kheradpour P, Zhang Z, Wang J, et al. 2015. Integrative analysis of 111 reference human epigenomes. Nature 518: 317-330.

Ruan H, Hacohen N, Golub TR, Van Parijs L, Lodish HF. 2002. Tumor necrosis factor- $\alpha$ suppresses adipocyte-specific genes and activates expression of preadipocyte genes in 3T3-L1 adipocytes: Nuclear factor- $\kappa \mathrm{B}$ activation by TNF- $\alpha$ is obligatory. Diabetes 51: 1319-1336.

Schmidt SF, Jørgensen M, Chen Y, Nielsen R, Sandelin A, Mandrup S. 2011. Cross species comparison of $\mathrm{C} / \mathrm{EBP} \alpha$ and PPAR $\gamma$ profiles in mouse and human adipocytes reveals interdependent retention of binding sites. BMC Genomics 12: 152.

Schmidt SF, Larsen BD, Loft A, Nielsen R, Madsen JG, Mandrup S. 2015. Acute TNF-induced repression of cell identity genes is mediated by $\mathrm{NF \kappa B}$-directed redistribution of cofactors from super-enhancers. Genome Res 25: 12811294.

Sears IB, MacGinnitie MA, Kovacs LG, Graves RA. 1996. Differentiation-dependent expression of the brown adipocyte uncoupling protein gene: Regulation by peroxisome proliferator-activated receptor $\gamma$. Mol Cell Biol 16: 3410-3419.

Sears DD, Hsiao A, Ofrecio JM, Chapman J, He W, Olefsky JM. 2007. Selective modulation of promoter recruitment and transcriptional activity of PPAR $\gamma$. Biochem Biophys Res Commun 364: $515-521$.

Siersbæk R, Mandrup S. 2011. Transcriptional networks controlling adipocyte differentiation. Cold Spring Harb Symp Quant Biol 76: 247-255.

Siersbæk R, Nielsen R, John S, Sung M-H, Baek S, Loft A, Hager GL, Mandrup S. 2011. Extensive chromatin remodelling and establishment of transcription factor 'hotspots' during early adipogenesis. $E M B O J$ 30: $1459-1472$.

Siersbæk MS, Loft A, Aagaard MM, Nielsen R, Schmidt SF, Petrovic N, Nedergaard J, Mandrup S. 2012a. Genome-wide profiling of peroxisome proliferator-activated receptor $\gamma$ in primary epididymal, inguinal, and brown adipocytes reveals depot-selective binding correlated with gene expression. Mol Cell Biol 32: 3452-3463.

Siersbæk R, Nielsen R, Mandrup S. 2012b. Transcriptional networks and chromatin remodeling controlling adipogenesis. Trends Endocrinol Metab 23: 56-64.

Siersbaek R, Baek S, Rabiee A, Nielsen R, Traynor S, Clark N, Sandelin A, Jensen ON, Sung MH, Hager GL, et al. 2014a. Molecular architecture of transcription factor hotspots in early adipogenesis. Cell Rep 7: 1434-1442.

Siersbæk R, Rabiee A, Nielsen R, Sidoli S, Traynor S, Loft A, Poulsen LLC, Rogowska-Wrzesinska A, Jensen ON, Mandrup S. 2014b. Transcription factor cooperativity in early adipogenic hotspots and super-enhancers. Cell Rep 7: 14431455.

Smith U, Gogg S, Johansson A, Olausson T, Rotter V, Svalstedt B. 2001. Thiazolidinediones (PPAR $\gamma$ agonists) but not PPAR $\alpha$ agonists increase IRS-2 gene expression in 3T3-L1 and human adipocytes. FASEB J 15: 215-220.

Soccio RE, Chen ER, Rajapurkar SR, Safabakhsh P, Marinis JM, Dispirito JR, Emmett MJ, Briggs ER, Fang B, Everett LJ, et al. 2015. Genetic variation determines PPAR $\gamma$ function and anti-diabetic drug response in vivo. Cell 162: 33-44.

Steger DJ, Grant GR, Schupp M, Tomaru T, Lefterova M, Schug J, Manduchi E, Stoeckert CJ Jr, Lazar MA. 2010. Propagation of adipogenic signals through an epigenomic transition state. Genes Dev 24: 1035-1044.

Step SE, Lim HW, Marinis JM, Prokesch A, Steger DJ, You SH, Won KJ, Lazar MA. 2014. Anti-diabetic rosiglitazone remodels the adipocyte transcriptome by redistributing transcription to PPAR $\gamma$-driven enhancers. Genes Dev 28: $1018-$ 1028.

Tam CS, Heilbronn LK, Henegar C, Wong M, Cowell CT, Cowley MJ, Kaplan W, Clément K, Baur LA. 2011. An early 
inflammatory gene profile in visceral adipose tissue in children. Int J Pediatr Obes 6: e360-e 363.

Tang X, Guilherme A, Chakladar A, Powelka AM, Konda S, Virbasius JV, Nicoloro SM, Straubhaar J, Czech MP. 2006. An RNA interference-based screen identifies MAP4K4/NIK as a negative regulator of PPAR $\gamma$, adipogenesis, and insulinresponsive hexose transport. Proc Natl Acad Sci 103: $2087-$ 2092.

Thurman RE, Rynes E, Humbert R, Vierstra J, Maurano MT, Haugen E, Sheffield NC, Stergachis AB, Wang H, Vernot B, et al. 2012. The accessible chromatin landscape of the human genome. Nature 489: 75-82.

Tontonoz P, Spiegelman BM. 2008. Fat and beyond: The diverse biology of PPAR $\gamma$. Annu Rev Biochem 77: 289-312.

Vernochet C, Peres SB, Davis KE, McDonald ME, Qiang L, Wang H, Scherer PE, Farmer SR. 2009. C/EBP $\alpha$ and the corepressors $\mathrm{CtBP} 1$ and $\mathrm{CtBP} 2$ regulate repression of select visceral white adipose genes during induction of the brown phenotype in white adipocytes by peroxisome proliferatoractivated receptor $\gamma$ agonists. Mol Cell Biol 29: 4714-4728.

Vierstra J, Rynes E, Sandstrom R, Zhang M, Canfield T, Hansen RS, Stehling-Sun S, Sabo PJ, Byron R, Humbert $\mathrm{R}$, et al. 2014. Mouse regulatory DNA landscapes reveal global principles of cis-regulatory evolution. Science 346: $1007-1012$.

Wakabayashi K-I, Okamura M, Tsutsumi S, Nishikawa NS, Tanaka T, Sakakibara I, Kitakami J-I, Ihara S, Hashimoto Y, Hamakubo T, et al. 2009. The peroxisome proliferator-activated receptor $\gamma /$ retinoid $\mathrm{X}$ receptor $\alpha$ heterodimer targets the histone modification enzyme PR-Set7/Setd8 gene and regulates adipogenesis through a positive feedback loop. Mol Cell Biol 29: 3544-3555.

Waki H, Nakamura M, Yamauchi T, Wakabayashi K, Yu J, Hirose-Yotsuya L, Take K, Sun W, Iwabu M, Okada-Iwabu M, et al. 2011. Global mapping of cell type-specific open chromatin by FAIRE-seq reveals the regulatory role of the
NFI family in adipocyte differentiation. PLoS Genet 7: e1002311.

Wang P, Renes J, Bouwman F, Bunschoten A, Mariman E, Keijer J. 2007a. Absence of an adipogenic effect of rosiglitazone on mature 3T3-L1 adipocytes: Increase of lipid catabolism and reduction of adipokine expression. Diabetologia 50: 654-665.

Wang Q, Li W, Liu XS, Carroll JS, Janne OA, Keeton EK, Chinnaiyan AM, Pienta KJ, Brown M. 2007b. A hierarchical network of transcription factors governs androgen receptordependent prostate cancer growth. Mol Cell 27: 380-392.

Weisberg SP, McCann D, Desai M, Rosenbaum M, Leibel RL, Ferrante AW Jr. 2003. Obesity is associated with macrophage accumulation in adipose tissue. $J$ Clin Invest 112: $1796-$ 1808.

Wernstedt Asterholm I, Tao C, Morley TS, Wang QA, DelgadoLopez F, Wang ZV, Scherer PE. 2014. Adipocyte inflammation is essential for healthy adipose tissue expansion and remodeling. Cell Metab 20: 103-118.

Whyte WA, Orlando DA, Hnisz D, Abraham BJ, Lin CY, Kagey MH, Rahl PB, Lee TI, Young RA. 2013. Master transcription factors and mediator establish super-enhancers at key cell identity genes. Cell 153: 307-319.

Wu J, Bostrom P, Sparks LM, Ye L, Choi JH, Giang AH, Khandekar M, Virtanen KA, Nuutila P, Schaart G, et al. 2012. Beige adipocytes are a distinct type of thermogenic fat cell in mouse and human. Cell 150: 366-376.

Yue F, Cheng Y, Breschi A, Vierstra J, Wu W, Ryba T, Sandstrom R, Ma Z, Davis C, Pope BD, et al. 2014. A comparative encyclopedia of DNA elements in the mouse genome. Nature 515: $355-364$.

Zhang B, Berger J, Hu E, Szalkowski D, White-Carrington S, Spiegelman BM, Moller DE. 1996. Negative regulation of peroxisome proliferator-activated receptor- $\gamma$ gene expression contributes to the antiadipogenic effects of tumor necrosis factor- $\alpha$. Mol Endocrinol 10: 1457-1466. 


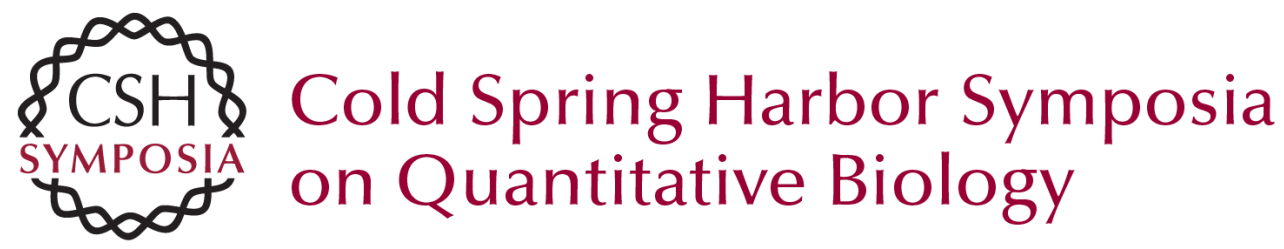

\section{Modulating the Genomic Programming of Adipocytes}

Anne Loft, Søren Fisker Schmidt and Susanne Mandrup

Cold Spring Harb Symp Quant Biol 2015 80: 239-248 originally published online October 2, 2015 Access the most recent version at doi:10.1101/sqb.2015.80.027516

References This article cites 84 articles, 34 of which can be accessed free at: http://symposium.cshlp.org/content/80/239.full.html\#ref-list-1

\section{License}

Email Alerting Receive free email alerts when new articles cite this article - sign up in Service the box at the top right corner of the article or click here. 